\title{
O FRANÇAIS LANGUE ETRANGËRE E A RE- DISTRIBUIÇÃO INTERNACIONAL DO ENSINO DE FRANCÊS: O CASO DO BRASIL
}

Felipe Dezerto

(CPII)

\section{RESUMO}

O presente trabalho tem por objetivo analisar o processo discursivo que sustenta a produção e a circulação dos saberes que integram manuais de ensino básico de francês no Brasil a partir da institucionalização do Français Langue Etrangère (FLE) na França, desde a segunda metade do século XX. Essa institucionalização é entendida aqui como política de língua, uma vez que incide sobre o ensino de forma a centralizar e controlar o que circula, e como circula, no interior do francês como campo disciplinar escolar de língua estrangeira. Para tanto, tomamos como material o livro Pixel 1, méthode de français, de Catherine Favret e Silvie Schmitt, editado em Paris, pela Editora Clé International, em 2011. Em relação ao seu lugar teórico, as análises situam-se no encontro da História das Ideias Linguísticas (Auroux, 2009 et alii) com a Análise do Discurso (Pêcheux [1975]1988 et alii Orlandi, 1996, 2003, 2005, et alii), assim como vem sendo desenvolvida no Brasil a partir dos trabalhos de Eni Orlandi (2001, 2002, 2007, et alii). Entendida, então, como processo discursivo, a institucionalização do FLE produz no ensino brasileiro imagens de uma língua francesa que toma a França como seu ponto de partida e de pertença, colocando a língua nacional francesa como o caminho que leva à antiga metrópole, apagando a heterogeneidade que compõe a comunidade francófona e os países onde o francês circula, com os mais variados estatutos. PALAVRAS-CHAVE: História das ideias linguísticas; análise do discurso; français langue étrangère; ensino de francês; livros didáticos. 


\section{Introdução}

Faire l'histoire d'une discipline scolaire, c'est s'attacher non seulement aux programmes et aux finalités de la discipline, non seulement aux pratiques éducatives et enseignantes qu'elle met en oeuvre, mais également aux effets réels et concrets qu'elle produit sur les élèves et sur la société qui les entoure. (CHERVEL, 2006, p. 7) ${ }^{1}$

O surgimento e a consolidação do Français Langue Étrangère (FLE) na França como campo disciplinar institucionalizado promove importantes impactos no ensino do francês pelo mundo. Neste trabalho, realizo uma análise do ensino escolar do francês contemporâneo, atendo-me ao caso da escola brasileira, tendo em vista a disciplinarização do FLE na França, a partir da segunda metade do século XX. Tomo como materialidade o livro didático Pixel 1, da editora Clé International, adotado desde 2014 pelo Colégio Pedro II, para o $6^{\circ}$ e $7^{\circ}$ anos do Ensino Fundamental.

A escolha do Colégio Pedro II como instituição de referência e ponto de partida se deve ao fato de que essa escola pública federal teve importante papel modelar no processo de disciplinarização do francês no Brasil, a partir de sua fundação em 1837, no Rio de Janeiro, pelo Império Brasileiro, em um momento em que a própria ideia de nação e a de escola brasileira estão em formação.

Esse processo de constituição de uma disciplina escolar de língua estrangeira foi objeto de minha tese de doutorado, intitulada Francês e Colégio Pedro II: um processo de construção de um campo disciplinar escolar (de 1838 a 1945), na qual analiso as principais reformas da educação brasileira desse período, os Programas Nacionais de Ensino do Colégio Pedro II e livros de ensino de francês em três recortes: a) o que chamei de momento fundacional da referida instituição; b) a passagem para a República e c) a Era Vargas.

Por essa razão, a relevância do Colégio Pedro II na constituição de um campo disciplinar escolar para o francês no Brasil. Retomo essa instituição para, aqui, analisar mais uma vez, o que é usado como livro didático de ensino de francês para o Ensino Básico: Pixel 1, méthode de français, de Catherine Favret e Silvie Schmitt, editado em Paris pela Editora Clé International, em 2011.

No período analisado na tese, os livros citados nos Programas Nacionais de Ensino do Colégio Pedro II eram também adotados pelos ou- 
tros liceus imperiais, que deveriam seguir esses programas de ensino. Só assim, as demais instituições de ensino do Brasil poderiam aprovar seus alunos para os cursos superiores recém-criados pelo Império. Hoje, os livros adotados pelo Colégio Pedro II não são mais impostos pela forma da lei, como no século XIX até a metade do século XX, mas a memória desta instituição e o lugar dos livros didáticos que ela adota têm um papel importante nas ações de escolha de livros didáticos, pela própria historicidade desse ensino e dessa instituição. Dito de outro modo, atualmente, o colégio não é mais um modelo imposto pela legislação, apesar de estar citado na constituição de 1988, mas o é por sua memória na/da educação brasileira.

Antes de prosseguir, em relação à sua posição teórica, este trabalho situa-se no encontro da História das Ideias Linguísticas (Auroux, 2009 et alii) com a Análise do Discurso (Pêcheux [1975]1988 et alii Orlandi, 1996, 2003, 2005, et alii), assim como vem sendo desenvolvida no Brasil a partir dos trabalhos de Eni Orlandi (2001, 2002, 2007, et alii).

É importante dizer que as análises aqui propostas, em conformidade com o quadro teórico em que se inserem, não têm o objetivo da exaustão ou da totalidade. Segundo Orlandi (1996, p. 12), nos processos de significação, "um objeto simbólico não é total, não é pleno. Algo sempre escapa". Objeto simbólico, pois a língua se inscreve na ordem do simbólico, em que os sentidos são fugidios, deslizam nos processos sociais e na história, se contrapõem, estão em relação a outros e, assim, são expostos a equívocos, a falhas e à incompletude, constitutivos de todo e qualquer processo histórico e semântico. Essa é a maneira como entendemos língua e sentido nessas análises.

\section{Os manuais e o processo de disciplinarização}

Trabalhar com livros didáticos remete-nos ao conceito de "instrumento linguístico". Segundo Auroux (2009, p.65), os instrumentos linguísticos descrevem e instrumentalizam as línguas na base de duas tecnologias: gramáticas e dicionários. Ainda segundo o autor,

a gramática não é uma simples descrição de uma língua natural; é preciso concebê-la também como um instrumento linguístico: do mesmo modo que o martelo prolonga o gesto da mão, transformando-o, uma gramática prolonga a fala natural e dá acesso a um corpo de regras e de formas que não figuram juntas na competência de um locutor (AUROUX, 2009, p. 70) 
Aqui, não analisamos gramáticas, mas tomamos o livro - ou manual - analisado também como instrumento linguístico por concebê-lo como algo que traz a língua sob essa representação de gramática e como algo imbricado na relação imaginária entre sujeito, sentido e língua estrangeira, relação esta que legitima o lugar do manual como representante da língua, em sua função imaginária de estabilização na direção da unidade linguística.

Puech (1998) chama de "manualização" o "processus par lequel les savoirs linguistiques s'exposent et se diffusent à des fins opératoires de transmission, appropriation, réinvestissement (...).."2 (PUECH, 1998, p. 15). Pensar o conceito de manualização implica dizer que interessa mais o processo que o produto em si. Não é o saber como produto final o que interessa, mas o processo discursivo que o coloca no interior dos manuais, sob os efeitos de sentido de um instrumento linguístico que representa a própria língua estrangeira da qual ele parte.

É, então, como instrumento linguístico que tomamos o manual aqui analisado, numa perspectiva historicizante, sustentada pela memória do Colégio Pedro II na educação brasileira. Inseridos nesse "domínio de memória" (COURTINE, 1999), os livros adotados pelo Colégio Pedro II são instrumentos linguísticos "fundadores" (ORLANDI, 2003) de um lugar para os manuais no ensino do francês no Brasil. Eles criam um vulto, um lastro, um efeito de continuidade, um lugar discursivo que define os modos como significam, para os sujeitos implicados nesse processo, os manuais que utilizamos no ensino de francês até hoje. São instrumentos linguísticos que fazem parte do processo de constituição de uma memória discursiva do ensino do francês no Brasil. E, quando se trabalha com o conceito de memória discursiva, é preciso entender que

uma memória não poderia ser concebida como uma esfera plena, cujas bordas seriam transcendentais históricos e cujo conteúdo seria um sentido homogêneo, acumulado ao modo de um reservatório: é necessariamente um espaço móvel de divisões, de disjunções, de deslocamentos e de retomadas, de conflitos de regularização... Um espaço de desdobramentos, réplicas, polêmicas e contra-discurso. (Pêcheux, [1983] 2007, p. 56)

Nessa perspectiva discursiva, não tomamos o conceito de memória como uma linearidade histórica retrospectiva que comporta uma totalidade. A memória que faz significar uma língua é algo da ordem do heterogêneo, marcado por esquecimentos, não ditos e silenciamentos. 
Por outro lado, o processo de manualização está imbricado no processo de constituição de uma disciplina, ou seja, a disciplinarização. O que está em jogo é a constituição de um aparelho didático para o ensino do francês no Brasil, que põe em relação língua estrangeira, instituição e sujeito.

Considerar o processo de construção de uma disciplina escolar de língua estrangeira nos ajuda a desnaturalizar as evidências dos conceitos de saber e de campo disciplinar, pensando que a forma da estabilização de saberes em determinados campos disciplinares possui espessura histórica. Nesse ponto, é preciso chamar a atenção para evidências que se produzem para os sujeitos envolvidos no processo de ensino de uma língua estrangeira: o campo disciplinar não é a língua estrangeira que ele representa. $\mathrm{O}$ campo disciplinar se instrumentaliza partindo dessa língua, mas não são coisas que se equivalem. O que estamos afirmando é que nem toda língua possui um campo disciplinar que lhe corresponda e que há uma não coincidência entre a língua e o campo disciplinar que toma essa língua sob a forma de saberes.

Considerando, então, que campo disciplinar possui seu estatuto próprio, a relação entre manuais de língua estrangeira e o campo disciplinar que os circunscreve é constitutiva da forma como se produz o ensino escolar de uma língua estrangeira.

\section{O surgimento do Français Langue Etrangère} (FLE): institucionalização e política de língua

Não poderíamos deixar de pensar as condições de produção ${ }^{3}$ dos sentidos que sustentam o ensino língua francesa, a partir do manual que analisamos. Por isso, pensar a institucionalização do FLE ajuda-nos a compreender a forma como a língua francesa se representa no ensino de francês brasileiro.

O surgimento do FLE realiza-se como ação do Estado francês, por meio de seus aparelhos voltados para a educação e a diplomacia, incidindo sobre o ensino do francês pelo mundo. Por essa razão, tomamos esse processo de institucionalização como uma política de língua que internacionaliza esse ensino. Para tanto, trazemos de Orlandi (1998), em seu deslocamento feito a partir do conceito de política linguística, o de política de línguas.

Sobre o conceito de políticas linguísticas, Calvet afirma: "Chamaremos políticas linguísticas um conjunto de escolhas conscientes referen- 
tes às relações entre língua(s) e a vida social, e planejamento linguístico a implementação prática de uma política linguística, em suma, a passagem ao ato". (2002, p. 145)

Distintamente, o conceito de "político das línguas" (ORLANDI, 1998) aponta para o fato de que o próprio conceito de política linguística passa pelo processo de divisão dos sentidos, podendo apontar para grandes ações de Estado até processos institucionais menos evidentes que se dão em microesferas de poder. Quando tratamos de políticas linguísticas, não podemos deixar de pensar que estas não podem se dar de forma dissociada da ideologia, bem como da imagem que se faz das línguas, para os sujeitos por elas interpelados. E falar em ideologia nesse quadro teórico faz-se colocar imediatamente a divisão dos sentidos.

Assim como Orlandi (1998), pensamos o conceito de políticas linguísticas como algo que aponta para as ações institucionais sobre as línguas, que engendram uma tentativa de controle imaginário sobre elas e seu suposto e ilusório funcionamento como unidade regulada, sem que se possa descartar o processo de divisão de sentidos que qualquer ação sobre as línguas instaura. Cria-se, sobre a língua, um controle que tenta fixar os sentidos, sob a ilusão de que se podem direcionar as práticas linguísticas e aprisionar os sentidos da língua, controlando seu funcionamento.

Também Mariani, a partir de Orlandi (1998), considera que

Há um caráter técnico, restritivo e regulador pressuposto na formulação de políticas linguísticas. O estabelecimento de regras para a efetiva utilização de uma língua ou para o silenciamento de outra organiza simultaneamente os espaços institucionais por onde as línguas circulam e o modo como elas circulam. Nessa medida, buscando domesticar o trânsito da heterogeneidade linguística, uma política linguística regulamenta a língua com que os sujeitos vão fazer a história significar. (MARIANI, 2004, p. 43)

Aponta-se, então, para uma injunção técnica de poder que pretende domesticar, controlar, uniformizar e homogeneizar as práticas linguísticas e as práticas de sujeitos submetidos a tais políticas. Isso posto, no processo de institucionalização de uma língua, e também de um campo disciplinar, o funcionamento das associações, congressos, e conhecimentos produzidos sobre ela desempenham um papel extremamente relevante na forma como são significados.

Também estamos de acordo com Pfeiffer (2007, p. 19) quando afirma que a constituição de um espaço institucional para uma língua "pode 
se dar em espaços particulares como o da Instituição que se configura por textualidades como gramáticas, dicionários, obras literárias, programas de ensino, Associações, entre outras."

Pensar a língua estrangeira como objeto simbólico que se liga ao funcionamento das instituições, produtoras de discursos e reguladoras, ajuda-nos a compreender como saberes linguísticos produzidos a partir de uma língua estrangeira se estabilizam, se institucionalizam e se disciplinarizam, ganhando um lugar de circulação legitimado. Disso decorre a possibilidade de se pensar o FLE como política de língua, que incide sobre o ensino do francês pelo mundo controlando e regulando a produção e a circulação de saberes em torno da língua francesa.

O processo de disciplinarização do FLE na França começa a tomar forma nas décadas de 50 e 60, após o início da descolonização, em um projeto dito de renovação cultural e linguística da França no exterior, que compreendeu a lançamento de pesquisas e a criação de lugares de referência que culminam no que chamamos hoje de FLE (COSTE, 1998, p. 82-83). Ainda segundo Coste (p.83), o ensino do francês para além das fronteiras da França profissionaliza-se de diferentes maneiras, desde a criação de cargos no exterior até a aparição de um grupo de especialistas em FLE, os FLEístas. O que ocorre é uma espécie de reorganização ou redistribuição internacional do trabalho de ensino do francês, após a institucionalização do FLE. Esse movimento de institucionalização consolida-se na década de 80, com o estabelecimento de um espaço universitário para o FLE.

No quadro 1, fazemos uma breve cronologia, apontando os principais fatos político- institucionais que se fazem relevantes e marcantes para o entendimento desse processo de institucionalização. 


\section{DATA FATO POLÍTICO-INSTITUCIONA OBSERVAÇÃO}

1954 Criação do Centre d'études du fran- Organizou uma pesquisa que culmiçais élémentaire nou no Français Fondamental, lista de palavras e indicações gramaticais para o ensino do francês no exterior

1957 A expressão "français, langue étran- Aos poucos a expressão perde a vírgère" aparece pela primeira vez na gula e as aspas e toma a forma atual revista Les cahiers pédagogiques

1958 Criação do CREDIF (Centre de Re- Associado à Ecole Normale Supérieucherche et d'Étude pour la Diffusion re de Saint-Cloud. Substitui o Centre du Français)

d'études du français élémentaire

1959 Criação do BEL (Bureau d'Étude et Dirigido por Guy Capelle, por inide liaison) ciativa do Ministère des Affaires Etrangères

1961 Publicação do primeiro número da re- A revista circula até os dias atuais, vista Le français dans le monde tratando do ensino do FLE no mundo inteiro.

1961 Publicação do relatório Recherche Relatório de 150 páginas oriundo universitaire et enseignement du das jornadas de estudo de 21 a 23 de français langue étrangère dezembro de 1961 no CIEP (Centre International d'Études Pédagogiques de Sèvres) sobre o contexto universitário e político do FLE. Revela uma relação entre linguistas e especialistas do ensino de FLE

Criação do BELC (Bureau pour Fusão do BEL e do CREC (Centre l'enseignement de la langue et de la de Recherches pour l'Enseignement culture françaises à l'étranger) de la Civilisation française à l'étranger) 


\section{DATA FATO POLÍTICO-INSTITUCIONAL OBSERVAÇÃO}

Início BELC e CREDIF

Encarregam-se da formação inicial

dos dos professores de FLE

anos

1980

1983 Novos diplomas nacionais passam a Momento decisivo na institucioser oferecidos em aproximadamente nalização do FLE - diplomas na30 universidades francesas cionais que certificam professores atestam a formação em FLE

1985 Criação do DELF e do DALF

Diplomas de proficiência em francês para estrangeiros

2006 Criação do DILF (Diplôme Initial de Para emigrados residentes na Langue Française) França 
Essa breve sequência de fatos político-institucionais não funciona aqui como uma tentativa de esgotar os acontecimentos relativos à institucionalização do FLE. Como já dito, não buscamos a totalidade, pois a incompletude é constitutiva dos processos discursivos. O que buscamos é fazer uma análise discursiva do processo de disciplinarização do FLE, pensando os efeitos que isso produz sobre o ensino do francês. Dessa maneira, apontar os movimentos de institucionalização desse campo disciplinar nos dá pistas do processo discursivo, e não de uma suposta totalidade analítica.

A partir dessa cronologia, podemos ver que a disciplinarização de FLE é um projeto político-pedagógico-científico-linguístico que ganha contornos na década de 1950, intensifica-se na década de 1980 e ainda continua produzindo seus efeitos, sem determinar por definitivo suas fronteiras, como todo e qualquer processo discursivo. Dizendo de outra maneira, quando nos referimos ao FLE, estamos tratando de um campo disciplinar, oriundo de políticas institucionais de ensino de uma língua estrangeira, e não de uma língua, como creem muitos professores de francês, tomados pela evidência do campo disciplinar como a própria língua estrangeira que a ele se liga. É por essa razão que nessas análises chamamos de francês o campo disciplinar de ensino de língua estrangeira, e não de língua francesa, que já tem outro estatuto. Chamamos o campo disciplinar de francês e a língua nacional da França de língua francesa. Essa distinção é de extrema importância para que possamos separar o que é da língua e o que é do campo disciplinar de ensino dessa língua. Não se pode considerá-los como equivalentes, como se se recobrissem.

Essas políticas de língua têm seu ponto de partida e centro, como se pode ver no quadro 1, na própria França. É a língua da nobreza europeia, língua instituída como nacional, língua cuja memória se liga a um ideal de civilização e progresso, que traz no bojo um importante legado do conhecimento científico, filosófico e literário (DEZERTO, 2013), que serve de ponto de partida para esse processo de internacionalização, centralizado pela França.

Com a consolidação do FLE, mesmo que os objetivos tenham sido promover a língua francesa no exterior, o que se promove é uma sistematização internacional do ensino do francês. Mesmo que a promoção da língua e da cultura vão no bojo desse processo.

Trouxemos para essa discussão esse breve histórico, pois o manual Pixel 1, publicado em 2011 na França, não escapa das injunções desse 
processo de disciplinarização do FLE. Trata-se das "condições de produção" (COURTINE, 2009) desse manual que analisamos a seguir.

\section{4 - A língua francesa: um mote para os espaços multiculturalistas internacionais}

O momento pós-guerras é decisivo na organização política dos países subjugados ao controle neocolonial francês. É a partir da década de 60 que os movimentos de independência ganham força e se concretizam. Rompem-se os laços político-neocoloniais com a metrópole europeia, a França. Porém, novas relações com a antiga metrópole criam-se em articulações supranacionais que reorganizam o papel dos Estados nacionais no cenário global.

No caso dos países onde se fez circular a língua francesa, foi a própria língua o mote para a criação da Francofonia, como organização interacional. Segundo Castello Branco,

(...) podemos compreender que a organização internacional é uma associação voluntária de sujeitos de direito internacional (quase sempre Estados), constituída mediante ato internacional (geralmente um tratado), de caráter relativamente permanente, dotada de regulamento e órgãos de direção próprios, cuja finalidade é atingir os objetivos comuns determinados por seus membros constituintes. (CASTELLO BRANCO, 2013, p.205)

O termo francofonia foi cunhado ainda no fim do século XIX pelo geógrafo francês, Onésime Reclus, para designar o conjunto de pessoas e países por onde a língua francesa circulava. Mas foi na década de 1970 que os Estados nacionais começaram uma organização política, que visava à consolidação de um espaço supranacional, ainda ligados pela língua, mas ampliando seus interesses como coletividade.

Essas ações supranacionais não são desconectadas de uma reorganização política mundial. Ainda conforme afirma Castello Branco,

Nos séculos XX e XXI, essa nova forma de união entre os Estados nacionais e os modernos ordenamentos jurídicos (e seus funcionamentos), referindo-nos aqui às formas dos Tratados internacionais - concebidos em conformidade com os conceitos do Direito Internacional clássico - viabilizam, criam, instituem e dão sustentação legal a essa nova forma de organização "estatal", a essa nova forma histórica espaço, que atrás denominamos como supranacional, que apresenta um funcionamento autônomo, autorizado e soberano que se estabelece 
com a "vontade" e o aval das nações envolvidas diretamente nos acordos e que prevalece sobre as decisões dessas mesmas nações. (CASTELLO BRANCO, 2013, p. 204 - aspas da autora)

No caso da Francofonia, passam a ocorrer os encontros de cúpula (os Sommets de la Francophonie), as ações supranacionais e a implementação de políticas em direção à globalização que vão configurar esse bloco da forma como ele se apresenta hoje: são 54 Estados membros, 23 Estados com o estatuto de observadores e 3 Estados associados ${ }^{5}$. No total, 80 países nos 5 continentes participam direta ou indiretamente da Francofonia.

Sob essas condições, produzem-se discursos multiculturalistas, que têm como objetivo, aparentemente, criar a unidade pela diferença. Surge, então, uma organização que deverá reunir toda a diversidade e a heterogeneidade de culturas e países ligados pela língua francesa, com o intuito de promover essa diferença e valorizar a heterogeneidade.

Nessa direção, os discursos multiculturalistas acabam por produzir um apagamento dos conflitos, das assimetrias, criando o efeito de um convívio não hierarquizado e não conflituoso entre as diferentes culturas.

Essas também são condições de produção para os materiais de ensino de francês produzidos pelo FLE. Nesses materiais, enquadra-se o manual aqui analisado: o Pixel. São materiais produzidos para o ensino do francês no interior dessa diversidade supranacional, em que a língua francesa perpassa seus estados membros, reunindo-os, servindo de mote, a princípio, para a promoção do multiculturalismo.

Abramos o Pixel.

\section{5 - PIXEL 1: imagens de uma língua estrangeira} com ensino internacional

Passamos agora, então, para as análises do livro Pixel 1, de Catherine Favret, editado pela Clé International, 2011, em Paris, adotado nos $6^{\circ} \mathrm{e}$ $7^{\circ}$ anos do ensino fundamental do Colégio Pedro II. Como já apontamos, os livros adotados pelo Pedro II não são mais impostos pela lei, como no século XIX até meados do século XX, mas eles significam, na educação brasileira, pela memória dessa instituição e pelo lugar discursivo que se criam para os livros didáticos do Colégio Pedro II.

É importante lembrar que a escolha dos livros didáticos das escolas públicas brasileiras atualmente passa pelo PNLD (Plano Nacional do 
Livro Didático), do governo federal. Porém, o francês não está incluído nesse plano, apesar de ser disciplina obrigatória do Ensino Fundamental e optativa no Ensino Médio do Colégio Pedro II, única instituição federal de ensino básico do Brasil. ${ }^{6}$

No Colégio Pedro II, a escolha do manual de francês a ser adotado fica a cargo dos professores do Departamento de Francês, que, periodicamente, recorre às três maiores editoras francesas ligadas ao FLE (Hachette, Clé International e Didier) e seleciona um dos manuais de seus catálogos.

Esse funcionamento do mercado editorial do FLE produz sentidos. Ele aponta mais uma vez para o papel centralizador da França no ensino do francês, no interior do que deveria ser uma promoção do multiculturalismo, reservando à nação francesa também o lugar legítimo de produção de conhecimento sobre sua língua. Língua esta que também é falada sobre os cinco continentes, mote para a criação da Organização Internacional da Francofonia.

Avancemos.

FIGURA 1: PIXEL 1 - UNITÉ 0

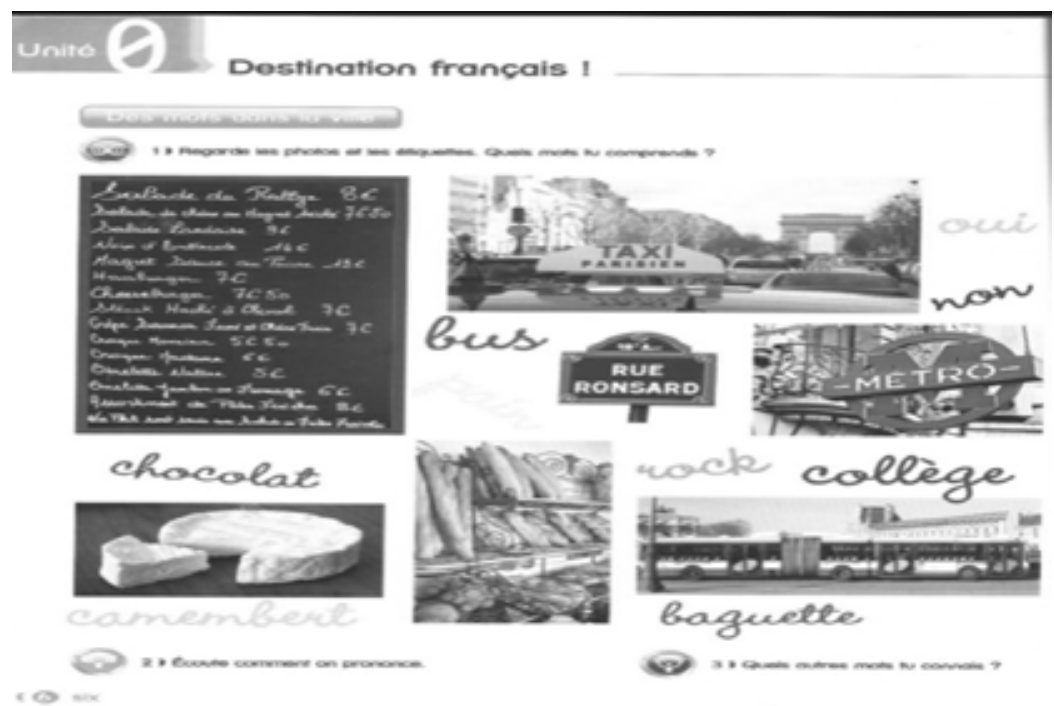




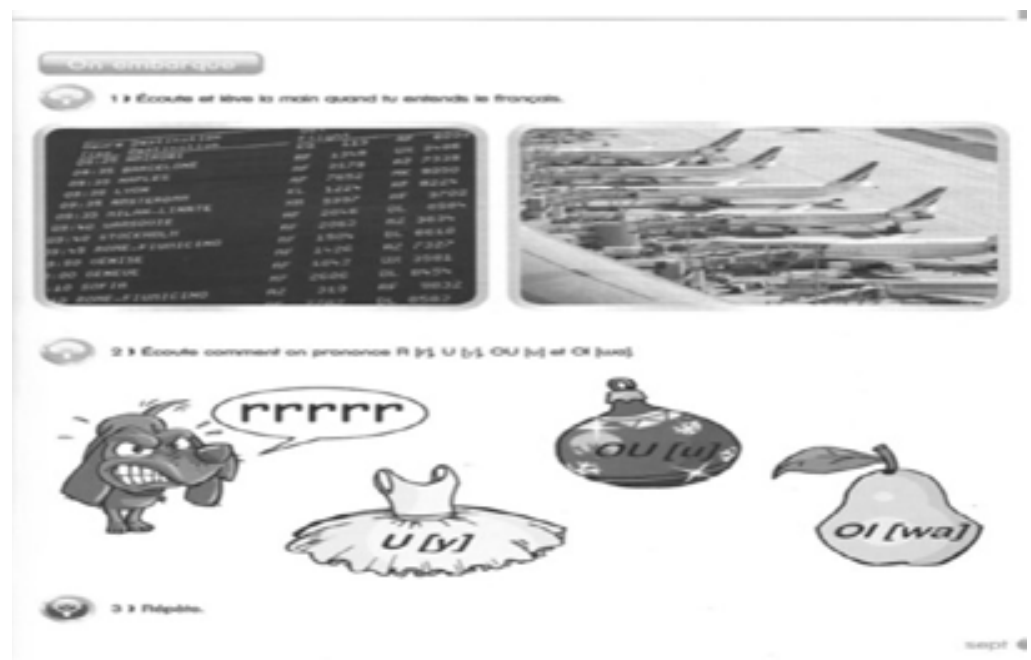

Observando a unidade 0, intitulada "Destination Français", que introduz o livro Pixel 1, temos, na primeira lição:

1 - um quadro que parece ser o menu de um restaurante com pratos da culinária francesa indicando-se os preços em euro;

2 - uma foto que enquadra, na Avenida des Champs Élysées, o teto de um táxi parisiense com o Arco do Triunfo ao fundo;

3 - uma placa tipicamente parisiense que indica Rue de Ronsard, 18 e arrondissement;

4 - a placa do metrô parisiense;

5 - um queijo camembert;

6 - baguettes e outros pães em uma prateleira de padaria;

7 - um ônibus parisiense que circunda a Place de la Concorde com o Jardin des Tuileries ao fundo.

Em meio às fotos, observamos palavras da língua francesa: bus, pain, chocolat, camembert, rock, collège, baguette, oui e non.

Na segunda página, podemos ver duas fotos:

1 - o quadro de partidas que parece ser do aeroporto Charles de Gaulle, em Paris, pelo fato de as destinações estarem em francês, em voos, em sua maioria pela Air France, companhia francesa de aviação; 
2 - a foto da pista, com seis aviões, sendo cinco da Air France.

3 - um exercício de pronúncia com alguns fonemas da língua francesa.

Primeiramente, voltamo-nos para as fotos das duas páginas da unité 0. Nelas, temos imagens de meios de transporte, orientação espacial, restaurante e alimentação. O que nos chama a atenção, de início, é como as "formações imaginárias" - entendidas aqui como o mecanismo imaginário que projeta no discurso representações dos lugares de onde se diz e para quem se diz (Pêcheux, [1975] 1988) - fazem significar a língua francesa em torno dos símbolos da capital francesa, Paris. Ao se trazerem para esse manual essas representações da cidade de Paris, provocam-se efeitos de sentido que colocam a língua francesa alinhada a certas imagens de cultura francesa que giram em torno de conhecidos símbolos da França e da cidade de Paris. Parece que representar a língua francesa nos coloca como destino a cidade de Paris.

$\mathrm{O}$ pareamento das imagens com as palavras, que aparecem como vocabulário também símbolo da cultura francesa, promove uma relação imagem-palavra que reforça a evidência ${ }^{7}$ do símbolo cultural francês, pela inequivocidade da imagem em sua relação de transparência com a palavra. E as palavras chocolat, collège e rock parecem ainda mais transparentes, uma vez que os significantes bastam por si só, sem que haja necessidade de imagens que lhes correspondam.

Nesse manual, pelas imagens ou pelas palavras que lhes correspondem, parece-nos que os sentidos que se ligam à língua francesa são emprestados da cultura da França, por meio de símbolos de uma memória que também leva à França. A Destination français é a França, e não outra parte do mundo francófono.

Passemos aos conteúdos. 
FIGURA 2: PIXEL 1 - Quadro de conteúdos

Grammaire

UNITE $\theta$
Destination fronçais I

\section{UNITE 1}

\section{Au collège}

pp. 12-13: Leçon 1 : La rentribe

pp. 14-15: Leçon 2 : En closse

pp. 16-17 : Leçon 3 : Des matieres a faire

pp. 18-19: Civilisation

p. 28 : Bilan

\section{UNITE 2}

Joyeux anniversoire I

pp. 22-23: Leçon 1 : ANo allo?

pp. $24-25$ : Leçon 2 : Je Finvite.

pp. 26-27 : Leçon 3 : Le jour J

p. 28 : Civilisation

p. 29 : Bilan

p. 30 : Le point sur la grammaire

\section{UNITE 3}

\section{Fotes de fomille}

pp. 32-33: Leçon 1: Photos de fomille

pp. 34-35: Leçon 2 : Notl of compagnie

pp. 36-37 : Lecon 3 : Beoucoup de cadecux |

pp. 38-39: Civilisation

p. 48 : Bilan

\section{UNITE 4}

\section{Loisirs jeunes}

pp. 42-43 : Leçon 1: Qu'est-ce qu'on fait ?

pp. 44-45: Leçon 2 : Comment on foit?

pp. 46-47 : Leçon 3 : Jai mal 1

p. 48 : Civilisation

p. 49 : Bilan

p. 50 : Le point sur la grammaire

\section{UNITE 5}

\section{La ville}

pp. 52-53: Leçon 1 : Une autre ville

pp. 54-55: Leçon 2 : Itinéroires

pp. 56-57 : Lecon 3 : Orientation ef transports

pp. 58-59: Civilisation

p. 68 : Bilan

\section{UNITE 6}

\section{Uno heure dans le monde}

pp. 62-63: Leçon 1 : Quelle heure est-it ?

pp. 64-65: Lecon 2 : Quel temps fait-il ?

pp. $66-67:$ Lecon 3 : Pendant ce temps-10.

p. 68 : Civilisation

p. 69 : Bilan

p. 78 : Le point sur la grammaire

Qui c'est ? - C'est / II (Elle) est

Articles indèfinis et définis

Le genre et le nombre

Tu / Vous

L'opostrophe

- L'interrogation avec est-ce que.

- $O n=$ Nous

- Quel, quels, quelle, quelles

- La negation (ne ... pas)

- Articles contractés avec a

- Chez

- Ciest/Ce sont

\section{- Pronoms toniques.} combien

- Negation : ne pas de...

- Articles contractés avec de

Comment

- Locolisation 1

(devant, sur, sous, etc.)

Pourquai? - Parce que

Conjugaison

(20)

- Se mioppelie

- Jhabite

\section{Pronoms}

personnels sujets

Verbes en -or

(aimer, adorer, détester...)

- Mots interrogatífs : qui, ov, quand.

- Adjectifs possessifs (1 seul possesseur)

- La quantité : peu de, beaucoup de, trop do

- Avoir

(tu peux, tu viens)

- Aller

- Etre

- " y a / In'y a pas de.

- Localisation 2

- Les cardinaux (oremier á cinquième)

- d/en+transports

.

\begin{tabular}{l|l} 
- Noms de pays avec les prépositions a & - Formes \\
(av/aux) et en & impersonnelles \\
- Nationalités & simples (il pleut. if \\
- Féminin des professions & fait beou...) \\
\end{tabular}

\section{Fonte própria}




\begin{tabular}{|c|c|c|c|}
\hline Phonétique & Thème-lexique & $\begin{array}{l}\text { Objectifs's de } \\
\text { communication }\end{array}$ & Civilisotion \\
\hline $\begin{array}{l}{[a]} \\
{[u]=o u} \\
|y|=u \\
{[\omega o \mid=o i}\end{array}$ & $\begin{array}{l}\text { - Abecidaire } \\
\text { - Noms de poys europetens } \\
\text { et froncophones }\end{array}$ & $\begin{array}{l}\text { - Reconnaitre le français } \\
\text { - Solver } \\
\text { - Se présenter }\end{array}$ & $\begin{array}{l}\text { - Francophonio : ov } \\
\text { est-ce qu' on parle } \\
\text { frangais? }\end{array}$ \\
\hline 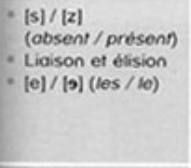 & $\begin{array}{l}\text { - Le college } \\
\text { - Caroctérisation } 1 \text { : (grand, penit, etc.) } \\
\text { - Compter de } 1 \text { a } 59 \\
\text { - Les matieres } \\
\text { - Les jours de la semaine }\end{array}$ & $\begin{array}{l}\text { - Detcrire quelquiun } \\
\text { - Poser des questions } \\
\text { sur les professeurs, les } \\
\text { copoins, les motieres } \\
\text { - Parler en classe : } \\
\text { les consignes et les } \\
\text { questions }\end{array}$ & $\begin{array}{l}\text { - Le college en } \\
\text { France } \\
\text { - Un colldge pas } \\
\text { comme les outres }\end{array}$ \\
\hline $\begin{array}{l}-[e] /[\varepsilon] \\
\text { (chez/fête) }\end{array}$ & $\begin{array}{l}\text { - La date } \\
\text { - L'Coge } \\
\text { - Lompter de } 58 \text { a } 160 \\
\text { - Les mois de rannée } \\
\text { - Corresse et le numero de teliephone } \\
\text { - Cotion } 2\end{array}$ & $\begin{array}{l}\text { - Telephoner a un copoin } \\
\text { I une copine } \\
\text { - Se presenter } \\
\text { - Dire la dote } \\
\text { - Inviter quelqu'un } \\
\text { - Accepter / Refuser une } \\
\text { invitation }\end{array}$ & $\begin{array}{l}\text { - Comment an fait la } \\
\text { fére en France? } \\
\text { - D'outres idtes } \\
\text { pour feter son } \\
\text { anniversaire (fêtes } \\
\text { danniversoire à } \\
\text { thème) }\end{array}$ \\
\hline $\begin{array}{l}\text { - U]/ [3] } \\
\text { (ocheter/ } \\
\text { manger) }\end{array}$ & $\begin{array}{l}\text { - La fomille } \\
\text { - Nobl et fótes de fin danné } \\
\text { - Les cadeoux } \\
\text { - Les vétements } \\
\text { - Les couleurs } \\
\text { - Quelques formes et matieres (rond, } \\
\text { carro. plastique. métol.) }\end{array}$ & $\begin{array}{l}\text { - Presenter sa fomille } \\
\text { - Demander quelque } \\
\text { chose a quelquiun } \\
\text { - Poser des questions sur } \\
\text { un objet } \\
\text { - Decrire un objet }\end{array}$ & $\begin{array}{l}\text { - Fútus de fin } \\
\text { drannde en France } \\
\text { - Publicite : Noél } \\
\text { sous les tropiques }\end{array}$ \\
\hline $\begin{array}{l}\text { Nosales : [a] / [5] } \\
\text { (dent/ front) }\end{array}$ & $\begin{array}{l}\text { Le corps } \\
\text { - Activites sportives et extrascolaires } \\
\text { - Verbes de mouvement (courir. } \\
\text { sauter, lancer...) } \\
\text { - En haut, en bas, en avant, en } \\
\text { arnière } \\
\text { - Le corps } \\
\text { - Jai mal a }\end{array}$ & $\begin{array}{l}\text { - Donner des ordres. } \\
\text { instructions, conseils } \\
\text { - Situer dans respoce } 1 \\
\text { - Parler de ses octivites } \\
\text { extrascolaires } \\
\text { - Exprimer ses sensations }\end{array}$ & $\begin{array}{l}\text { - La capoeira : un } \\
\text { sport a la mode }\end{array}$ \\
\hline $\begin{array}{l}\text { - }[\mathrm{b}] /[\mathrm{v}] \\
\text { (bison/ vison) } \\
\text { - Le e- muet et } \\
\text { los lettres quion } \\
\text { eccrit mais quion } \\
\text { ne prononce pas }\end{array}$ & $\begin{array}{l}\text { - La ville (magasins, centre } \\
\text { commercial.) } \\
\text { - Les tronsports (train, bus, metro..) }\end{array}$ & $\begin{array}{l}\text { - Situer dans respace } 2 \\
\text { - Demonder et donner } \\
\text { une direction, un chemin } \\
\text { - Suivre un itineraire }\end{array}$ & $\begin{array}{l}\text { - Forum : Jadore } \\
\text { ma ville I } \\
\text { (Montreat, } \\
\text { Bruxelles, Dokar) }\end{array}$ \\
\hline $\begin{array}{l}-[(\omega] /[\emptyset] \\
\text { (servour/, } \\
\text { serveuse) }\end{array}$ & $\begin{array}{l}\text { - Lheure } \\
\text { - Les points cardinaux } \\
\text { - Les saisans } \\
\text { - La mettéo } \\
\text { - Les notionolites } \\
\text { - Les professions } \\
\text { - Francophonie }\end{array}$ & $\begin{array}{l}\text { - Demander et donner } \\
\text { Theure } \\
\text { - Donner son emploi du } \\
\text { temps } \\
\text { - Dire le temps quil foit } \\
\text { - Donner des informations } \\
\text { sur un poys }\end{array}$ & $\begin{array}{l}\text { - Interview : La vie } \\
\text { dartisto }\end{array}$ \\
\hline
\end{tabular}


Nesse quadro de conteúdos, que divide o livro em 7 unidades, os saberes sobre a língua francesa estão apresentados em grammaire, conjugaison, phonétique, thème-lexique, objectifs de comunication e civilisation $^{8}$. Não entraremos nas injunções do avanço da presença da linguística que influenciam tal enquadramento da língua, por uma questão de objetivos. Vamo-nos concentrar no que o manual traz como civilisation.

Se observamos os temas que aparecem nessa rubrica, temos:

Unité 0 - Francophonie: où est-ce qu'on parle français?

Unité 1 - Le collège en France; Un collège pas comme les autres

Unité 2 - Comment on fait la fête en France?; D'autres idées pour fêter son anniversaire (fêtes d'anniversaire à thèmes)

Unité 3 - Fête de fin d'année en France; Publicité: Noël sous les tropiques

Unité 4 - La capoeira: un sport à la mode

Unité 5 - Forum: J'adore ma ville! (Montréal, Bruxelles, Dakar)

Unité 6 - Interview: la vie d'artiste ${ }^{9}$

Dos temas das seções de civilização, só se aponta para outro lugar que não seja a França na Unidade 0 e na Unidade 5. Todas as demais unidades tematizam a França ou partem da França como referência. Até mesmo a Unidade 4, que fala de Capoeira, trata de um clube de esportes da cidade de Rennes, na França, a partir do qual se pode "découvrir le Brésil" (conhecer o Brasil).

Assim, aproximadamente $30 \%$ do que pareceria apontar para a diversidade e para a heterogeneidade sob a égide do mundo da Francofonia não mostra nenhuma instabilidade em relação aos modos de circulação da língua francesa pelo mundo, nenhuma heterogeneidade que crie choque entre as diversas culturas aí implicadas, enfim, nada que perturbe a unidade imaginária da língua da França e da língua francesa, que, consequentemente, é mostrada como não conflituosa em toda a comunidade francófona, quando ela aparece.

Mais uma vez, parece que o ensino dessa língua que leva consigo a promoção de uma cultura, e não de várias, se produz sob os efeitos de uma "língua imaginária" (ORLANDI, 2002), uma língua sem tensões e sem heterogeneidades. Assim, é representada a língua da França, uma língua que pode ser falada pelas mais diferentes culturas, nos 5 continentes, sem sofrer tensões nem efeitos de heterogeneidade, uma língua capaz de apagar as heterogeneidades voltando-se para a França como seu território 
de partida, seu ponto de referência. Mais uma vez, a França está no centro de cultura, representada como saberes manualizados de civilização.

\section{Considerações finais}

A institucionalização do FLE na França configurou-se como um projeto político-linguístico de internacionalização do ensino de Francês no mundo, em um momento em que ocorre também uma reorganização internacional dos Estados. Houve, nesse processo, uma redistribuição internacional do ensino, que vai desde a produção de conhecimento até a criação de cargos diplomáticos de promoção da língua francesa nos mais variados países onde se ensina o francês. Esse processo caminha junto com a supranacionalização dos Estados francófonos.

O FLE e a redivisão internacional do trabalho de ensino do francês dá um enquadre específico para a autoria e a publicação dos manuais, centralizando o processo na França, desde a produção do saber até a distribuição dos manuais. Pelas análises do livro Pixel 1, temos um ensino que produz uma língua francesa como veículo da cultura da França, colocando a França como centro e ponto de referência. É a promoção da cultura francesa representada por símbolos dessa cultura que circulam na memória da língua.

Castello Branco (2013, p. 92) lembra-nos de que foi com uma filosofia do monoculturalismo/monolinguismo que o Estado francês procurou impor, a diferentes grupos (de línguas diversas: normando, picardo, catalão, provençal, gascão, bretão, basco etc.), a língua francesa falada pela antiga aristocracia e pela nova elite que chegava ao poder, após a Revolução de 1789. Ainda segundo a autora (CASTELLO BRANCO, 2013), a luta política materializou-se pela aniquilação da multiplicidade de línguas vernáculas (os patois) faladas em praticamente todo o Estado francês, com exceção de Paris, depreciando-as estrategicamente em relação à língua francesa. Isso porque os patois estavam "vinculados ao Antigo Regime", seus falantes eram "bárbaros", eram tidos como "línguas mortas", que deveriam ser guardadas em "museus", pois seriam parte da "riqueza histórica" do país. $\mathrm{O}$ francês era mostrado como a língua que trazia a "claridade" a todos os que a dominavam, sendo somente por meio dessa língua que o povo francês poderia entender o que é a liberdade (contra a opressão feudal) e, assim, ao tornarem-se cidadãos franceses (tendo como importante a noção de pertencer à nação), poderiam "civilizar-se" (falar francês era mostra de civilidade, de pertencimento a uma 
nação livre que surgia) e ter acesso às novas leis e reformulações da nova sociedade.

Em outras condições de produção, essa memória de imposição e apagamentos da língua do Estado francês parece reverberar no interior dos discursos multiculturalistas de promoção da diversidade. São os sentidos de língua das luzes que sustentam essa memória. Parece não haver grandes rupturas na forma como a língua e a civilização francesas se produzem nos manuais e circulam pelo mundo. Os sentidos que se produzem continuam apontando para a França, como estado centralizador, fazendo com que continue ressoando uma memória da língua francesa que aponta para um modelo, um centro, uma civilização, assim como pude também verificar na tese, durante as análises do ensino de francês no Brasil, nos séculos XIX até meados do século XX.

Se a descolonização destituiu a França de seu lugar de metrópole, o FLE parece ter-lhe concedido o lugar de centro de produção de conhecimento, de especialização e de distribuição do ensino do francês pelo mundo, não deixando transparecer nenhuma heterogeneidade ligada à língua e à cultura francesas. Como campo disciplinar, o FLE trabalha, administra as heterogeneidades, fazendo o francês significar como uma língua imaginária que apaga a heterogeneidade dessa língua ao redor do mundo. Trata-se mesmo de uma política de administração de diferenças sob a forma de um campo disciplinar de língua estrangeira.

No caso do Brasil, não fazemos parte da Francofonia, embora a língua francesa circule em nosso território desde antes da colonização portuguesa, conforme nos mostram os relatos dos viajantes franceses. Mas, na condição de brasileiros, professores de francês, sujeitos implicados no processo de ensino de francês no Brasil, estaríamos fadados a receber essa herança pós-colonial? Ou haveria outro lugar ou outros modos de se produzir e distribuir conhecimento sobre a língua francesa que efetivamente valorizem sua diversidade e sua heterogeneidade? Não seria esse o caminho da alteridade tão preconizado pelo ensino da língua estrangeira? Paramos nessas provocações, esperando que elas suscitem, cada vez mais, reflexões. 


\section{THE FRANÇAIS LANGUE ETRANGÈRE AND THE IN- TERNATIONAL REDISTRIBUTION OF THE FRENCH LANGUAGE TEACHING: THE BRAZILIAN CASE}

\section{ABSTRACT}

The present work aims at analyzing the discursive process that sustains the production and circulation of the knowledge that has integrated the middle school French language teaching manuals in Brazil based on the institutionalization of the Français Langue Etrangère (FLE) in France, since the second half of the 20th century. This institutionalization is here understood as language policy, once it focuses on the teaching process so as to centralize and control what circulates within the French language as a foreign language school subject. Therefore, we selected as material the book Pixel 1, méthode de français, by Catherine Favret and Silvie Schmitt, edited in Paris by the Editora Clé International, in 2011. Regarding their theoretical background, these analysis can be placed in the encounter of the History of Linguistic Ideas (Auroux, 2009 et alii) with the Discourse Analysis (Pêcheux [1975]1988 et alii Orlandi, 1996, 2003, 2005, et alii), as it has been developed in Brazil from Eni Orlandi's works (2001, 2002, 2007, et alii). Understood as a discursive process, the institutionalization of the FLE in the Brazilian education produces images of a French language that elects France as its starting and belonging point, placing the national French language as the way that leads to the old metropolis, erasing the heterogeneity that composes the French community and the countries where French circulates, with different statutes. KEYWORDS: History of Linguistic Ideas; discourse analysis; français langue étrangère; French language teaching; textbooks.

\section{REFERÊNCIAS BIBLIOGRÁFICAS}

AUROUX, S. A revolução tecnológica da gramatização. Trad: Eni Orlandi. 2ed. Campinas, SP: editora da Unicamp, 2009.

CASTELLO BRANCO. Luiza Kátia A. A língua de além-mar: sentidos à deriva 
- O discurso da CPLP sobre língua portuguesa. Tese de doutorado. Campinas: UNICAMP, 2013.

CHERVEL, André. Histoire de l'enseignement du français du XVIIe au XXe siècle. Paris: Éditions RETZ, 2006.

COSTE, Daniel. Recherche universitaire et enseignement du français langue étrangère : à propos d'une recherche de 1961. In: Revista Langue Française. No 117, 1998. 82-98

COURTINE, Jean-Jacques. O chapéu de Clémentis. In: INDURSKY, F. e FERREIRA, M.C.L. Os múltiplos territórios da Análise do Discurso. Porto Alegre: Ed. Sagra Luzzatto, 1999.

Análise do discurso político: o discurso comunista endereçado aos cristãos. São Carlos: EdUFSCar, 2009.

DEZERTO, Felipe. Francês e Colégio Pedro II: um processo de construção de um campo disciplinar escolar (de 1838 a 1945). Tese de doutorado. Niterói: UFF, 2013.

FAVRET, C. \& SCHMITT, S. Pixel 1: méthode de français. Paris: Clé International, 2011.

MARIANI, B. Discurso e instituição: a imprensa. In: Revista Rua, Campinas, SP. No 5,1999 , p. $47-61$.

Colonização linguística: línguas, política e religião no Brasil (séculos XVI a XVIII) e nos Estados Unidos (século XVIII). Campinas, SP: Pontes, 2004.

ORLANDI, Eni. Interpretação: autoria, leitura e efeitos do trabalho simbólico. Petrópolis: Vozes, 1996.

. Ética e política linguística. In: Línguas e instrumentos linguísticos. Coleção História das Ideias Linguísticas. Campinas: Pontes, jan-jun, 1998: 7-16.

História das ideias linguísticas: construção de um saber metalinguístico e constituição da língua nacional. Campinas, SP: Pontes; Cárceres, MT: UNEMAT Editora, 2001.

Língua e conhecimento linguístico: para uma história das ideias no Brasil. São Paulo: Cortez, 2002.

A linguagem e seu funcionamento: as formas do discurso $-4^{\mathrm{a}}$ ed. Campinas, SP: Pontes, 2003.

(org). Discurso fundador: a formação do país e a construção da identidade nacional. $3^{\mathrm{a}}$ ed., Campinas, SP: Pontes, $2003 \mathrm{~b}$. 
Análise de discurso: princípios e procedimentos. Campinas: SP: Pontes, 2005.

. (org). Política linguística no Brasil. Campinas, SP: Pontes, 2007.

ORLANDI, Eni \& GUIMARÃES, Eduardo (Org). Institucionalização dos estudos da linguagem: a disciplinarização das ideias linguísticas. Campinas, SP: Pontes, 2002.

PÊCHEUX, Michel. Semântica e discurso: uma crítica à afirmação do óbvio. Tradução Eni Orlandi. Campinas, SP: Editora da UNICAMP, [1975] 1988.

. Papel da memória. In: ACHARD, P. (et al.). Papel da memória. Tradução: José Horta Nunes. 2a ed. Campinas, SP: Pontes, [1983] 2007.

PFEIFFER, Claudia. A linguística nas associações: um recorte discursivo. In: ORLANDI, Eni (org). Política linguística no Brasil. Campinas, SP: Pontes, 2007.

PUECH, Christian. Manuélisation et disciplinarisation des savoirs de la langue: l'énonciation. In: COLLINOT, A. e PETIOT, G. (org). Manuélisation d'une théorie linguistique: le cas de l'énontiation. Paris: Presse de la Sorbonne Nouvelle, 1998.

PUREN, C. Histoire des méthodologies des langues. Paris: Clé international, 1988.

ROCHA, D. Da linguística aplicada à didática das línguas: pela diversidade de pesquisas favoráveis ao trabalho com língua estrangeira. (no prelo)

. "A constituição de sentido nas fronteiras do eu: memória da língua e língua da memória”. Letras (UFSM), Santa Maria, v. 26, p. 119-130, 2003.

\section{NOTAS}

${ }^{1}$ Fazer a história de uma disciplina escolar é se voltar não somente para os programas e para a finalidade da disciplina, não somente para as práticas educativas e de ensino que essa história engendra, mas também para os efeitos reais e concretos que ela produz sobre os alunos e sobre a sociedade que os cerca.

${ }^{2}$ Processo pelo qual os saberes linguísticos se expõem e se difundem com fins operatórios de transmissão, apropriação, reinvestimento (...) (tradução minha)

${ }^{3}$ Scherer (2003, p. 122), a partir de Courtine (2009), nos esclarece que “ ... as condições de produção (quadro institucional, aparelho ideológico, representações que subjazem, conjunturas políticas, relação de força, efeitos estratégicos procurados) não formam um simples contexto de circunstâncias que se alojam de 
maneira simples no discurso do sujeito, mas que o constituem e ao constituí-lo são recuperáveis (...) a partir da memória discursiva.

${ }^{4}$ As informações que compõem esse quadro foram retiradas de Coste (1998) e Rocha (no prelo).

${ }^{5}$ Consultado em http://www.francophonie.org/-80-Etats-et-gouvernements-.html, em 02 de fevereiro de 2016.

${ }^{6}$ As demais instituições ligadas ao governo federal que trabalham com esses segmentos são de ensino técnico e tecnológico.

${ }^{7}$ Para Pêcheux ([1975] 1988), a produção de evidências está ligada ao efeito ideológico que faz com que o sentido pareça óbvio, transparente, natural, apagando sua historicidade constitutiva.

${ }^{8}$ Gramática, conjugação, fonética, tema-léxico, objetivos de comunicação e civilização (tradução minha).

${ }^{9}$ Unidade 0 - Francofonia: onde se fala francês ?; Unidade 1 - O colégio na França, um colégio diferente dos outros ; Unidade 2 - Como se festeja na França? Outras ideias para festejar seu aniversário (festas de aniversário temáticas); Unidade 3 - Festa de fim de ano na França; Publicidade: Natal abaixo dos trópicos; Unidade 4 - A capoeira: um esporte na moda; Unidade 5 - Forum: Eu adoro minha cidade! (Montreal, Bruxelas, Dakar); Unidade 6-Entrevista: a vida de artista.

Recebido em: 16 de janeiro de 2016

Aceito em: 09 de maio de 2016 